\title{
POR QUÉ IR A LA ESCUELA E IMPLICANCIAS PARA LA JUSTICIA SOCIAL: ESTUDIO DE CASO
}

\section{WHY GOING TO SCHOOL? IMPLICATIONS FOR SOCIAL JUSTICE IN EDUCACION: A CASE STUTY}

Carmen Sepúlveda Parra ${ }^{1}$ Adrian Dias de Oliveira ${ }^{2}$

\begin{abstract}
RESUMEN: Este trabajo presenta los resultados de una investigación, cuyo objetivo es conocer la concepción de escuela y las razones para asistir a clases entre escolares de un Centro ubicado en la periferia de Santiago de Chile y que atrae a famílias de sectores socioeconómicos bajo y medio bajo. Se realiza una investigación cualitativa, utilizando entrevistas grupales con asociación libre de palabras y dibujos, en 6 grupos cursos de estudiantes de tercero a octavo básico. Los datos se procesan mediante el análisis de contenido temático. Se encontró que la concepción de la escuela oscila entre ser un lugar para aprender, entretenido y divertido; una segunda familia, ser un lugar aburrido y donde ir a pelear. Las razones para ir a clases son académicas, prosociales e instrumentales. Se discute sobre el reconocmiento de la diversidad y sus limitantes; el abuso de poder entre iguales, el concepto de robo y la naturalización de estos fenómenos; la ausencia o puesta en duda de normas sociales y el "dejar hacer" favorece la expresión y la acción individual, necesaria pero insuficiente para la construcción de sentidos colectivos. Se reflexiona sobre las implicancias de la socialización para el fomento de la justicia social en la escuela.
\end{abstract}

Palabras claves: Justicia social. Socialización. Asistir a clases. Reescolarización.

ABSTRACT: This paper presents the results of a research study, which aims knowing the conception and the reasons for going to school among children who attend a School located in the outskirt of Santiago, attracting very low and low income families. A qualitative research was conducted among classes from third to eighth grade of primary education, by applying group interviews, using free word associations and drawings. Data was analyzed using theme content analysis where the conception of the School found varies from seeing it as a place for learning, amusing and fun; also as a second home; however, it is repeatedly described as boring place and a place for fighting. Children go to school for academic, pro social and instrumental reasons. The recognition of diversity and its shortcoming are discussed; the abuse of power among equals, the concept of theft and the naturalization of these phenomena; the absence or questioning of social norms and the less affair school's policy promote self-expression and individual action, both necessary but insufficient for the construction of collective senses. We offer a reflection about the finding's implications to promote social justice in education.

Keywords: Social justice. Socialization. School attendance. Rentry students.

\footnotetext{
${ }^{1}$ Antropóloga y Dra. en Psicología. Académica e investigadora. Escuela de Sociologia. Universidad Católica Silva Henríquez Santiago de Chile.

${ }^{2}$ Socióloga Dra. e Pós-Doutora em Educación e investigadora. Universidad Católica de São Paulo, Brasil.
} 


\section{Universidade do Extremo Sul Catarinense \\ Revista lbero-Americana de Humanidades, Ciências e \\ Educação \\ unesc

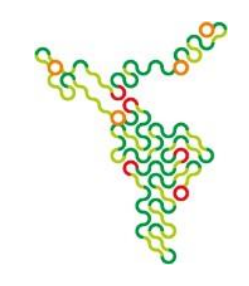

\section{Introducción}

El ausentismo y la deserción escolar entre niños provenientes de sectores vulnerables es un problema que en Chile se aborda con acciones redistributivas como becas, vouchers por asistencia, entre otros, logrando la escolarización sobre un 90 por ciento en enseñanza básica, sin que las funciones de la socialización secundaria se alcancen, entre otras, aprender a convivir en la diversidad y al desarrollo de la ciudadanía. En Chile, la educación obligatoria es hasta los 18 años de edad; está formada por dos niveles, básica o primaria que se extiende por 8 años y la educación media con 4 años. Algunos jóvenes reingresan al sistema escolar, al nível que corresponda según la progresión alcanzada, como forma de evitar sanciones o para tener una actividad comprobable ante eventuales problemas con la justica.

La educación básica en Chile es de tres tipos según la fuente de financiamiento: municipal o pública, particular subvencionada -vigente en 2017 - y educación privada. El aporte de la familia a la educación genera una fuente de desigualdad, al sentir falta de oportunidades, el bajo rendimiento académico y la conflictividad de los estudiantes. (GOICOVIC, 2002; PNUD, 2017).

La Escuela estudiada es de tipo particular subvencionada; parcialmente financiada por el Estado y las familias, administrada por un sostenedor desde el 2015 y es foco de atracción para familias de nivel socioeconómico bajo y medio bajo en Santiago de Chile. La nueva administración de la Escuela, llega para evitar su cierre debido al sostenido bajo rendimiento académico, establece la misión de favorecer el desarrollo integral de los escolares, para lograr la reinserción escolar y evitar la deserción.

Para cumplir su misión esta Escuela se ha empeñado en crear y emplear estrategias pedagógicas innovadoras; la incorporación de actividades artísticas -talleres- llevados a cabo por talleristas o artesanos de la especialidad, de manera simultánea, a modo de co-docencia, con la enseñanza de las materias oficiales impartidos por maestras y maestros; se suma una decidida inserción en la comunidad con intervenciones artísticas y pedagógicas.

Esta investigación es parte de una alianza Escuela-Universidad, a través de un programa de Aprendizaje en Servicio. Los estudiantes de cuarto año de la carrera de Sociología y la docente respectiva, asumen la tarea de buscar respuestas a las inquietudes del equipo directivo de la Escuela y que, se traduce en los siguientes objetivos: conocer la concepción que poseen los escolares sobre la escuela y las razones de asistir a clases. 


\section{Universidade do Extremo Sul Catarinense \\ Revista lbero-Americana de Humanidades, Ciências e \\ Educação \\ Unesc Produção e democratização do conhecimento na lbero-América}

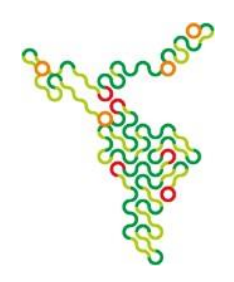

\section{Marco conceptual}

En esta investigación se asume el carácter construido de la realidad (BERGER Y LUCKMAN, 1976). Esto quiere decir que, para vivir y estar en el mundo, todas las personas elaboramos una interpretación de éste. El contenido de estas interpretaciones se basa en una serie de experiencias previas que funcionan como esquemas de referencias "conocimientos a la mano" o “conocimientos de receta". Este conocimiento se expresa en el lenguaje cotidiano; por tanto, para comprender qué está ocurriendo en una institución o situación dada, es necesario averiguar qué significan los conceptos para los individuos que orientan su conducta en ella.

Si deseamos comprender qué frena la deserción escolar o facilita la reescolarización podemos acceder a las "tipificaciones" o expresiones en el lenguaje cotidiano, ya que los contenidos de dichos conceptos permiten develar los significados en juego; las razones de ser que anteceden la acción y el imaginario de interpretaciones posibles.

El proyecto educativo de la Escuela estudiada asume la tarea de favorecer la socialización secundaria de los niños y cumplir las funciones que tradicionalmente se le asigna a la educación en toda sociedad, entre estas: la transmisión cultural, formación ciudadana y legitimación de la forma de organización de la sociedad, formación, movilidad social y custodia de la infancia.

Teniendo presente que la educación en general es la encargada de formar la generación de reemplazo, en esta presentación se opta por focalizar la reflexión en términos de la formación ciudadana y las formas de convivencias que promuevan la Justica social.

Se adopta por la concepción de Justicia social en educación propuesta por FRASER (2008); ésta contiene tres dimensiones, a saber: de redistribución, reconocimiento y representación. La redistribución hace referencia a la distribución de los bienes primarios que se encuentran en la sociedad, dando más a quien -por su condición de partida- más lo necesita (MURILLO Y HERNÁNDEZ-CASTILLA, 2011; RAWLS, 2008); el reconocimiento se concibe como la ausencia de dominación cultural, no reconocimiento e irrespeto por las diferencias culturales, sociales y personales; mientras que la representación implica la promoción del acceso y la equidad para asegurar la plena participación en la vida social, para aquellos que han sido sistemáticamente excluidos (MURILLO Y HERNÁNDEZ-CASTILLA, 2011).

La justicia social implica mejor distribución económica, mejor reconocimiento del valor de las diferencias y mayor representación en la vida social (CUENCA, 2012). Si no se cautela el 


\section{Universidade do Extremo Sul Catarinense \\ Revista lbero-Americana de Humanidades, Ciências e \\ Educação \\ Unesc Produção e democratização do conhecimento na lbero-América}

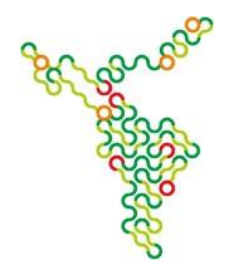

balance de estos tres verbos se pone en jaque la consecución de ésta y la presencia de injusticias en la educación y en la escuela.

En este caso, la concepción que poseen los estudiantes de la escuela y las razones para asistir permite identificar los saberes del sentido común en juego y desde allí reflexionar sobre las implicancias en la socialización; el aprendizaje de las formas de vida en la sociedad, que favorezca la justicia social.

Esta investigación, si bien posee la limitación de partir desde los escolares, permite tener una aproximación a las concepciones y correspondientes acciones que permean el currículo oculto, el no explícito que se expresa en la vida diaria de la escuela; información de utilidad para la toma de decisiones de la comunidad escolar.

\section{Metodología}

Se efectuaron 18 entrevistas grupales en 6 grupos en cursos de tercero a octavo básico o primario; cuyas edades oscilan entre 8 y 16 años. Se emplea la técnica de asociación libre; se les pide a los estudiantes que respondan dos preguntas: ¿Si te digo Escuela (nombre), qué palabras se te ocurren? ¿Por qué asistes a la escuela? Se les proporciona papel y lápices de colores para dibujar sus respuestas o escribir libremente. Luego responden oralmente y/o relatan el significado de sus dibujos.

Los datos se analizan empleando el análisis de contenido temático (CONDE, 2009), que incluye la segmentación y reagrupación de la información en torno a temáticas y cuya función final es aportar en la creación de un análisis teórico.

En la recolección de la información se emplean resguardos éticos, principalmente el asentimiento de los escolares, los que podían ingresar o salir de la actividad sin consecuencias. Los datos fueron recogidos por estudiantes universitários y profesor del aula se mantenía fuera de la sala o realizando alguna actividad ajena al estudio.

\section{Resultados}

a) La concepción de la Escuela

La concepción de Escuela se agrupa bajo três conceptoss: la Escuela como família; la Escuela bonita y entretenida o "bacán" 1 , y, aburrida o "Fome ${ }^{2}$ "

- La Escuela concebida como segundo hogar, una familia o guardería. Ésta, es un lugar donde 


\section{Universidade do Extremo Sul Catarinense \\ Revista lbero-Americana de Humanidades, Ciências e \\ Educação \\ unesc

se encuentra seguridad, se aprende y hay cuidado o protección. El concepto guardería tiene dos acepciones; un lugar de protección a los menores, además, refleja la diferencia de edades que coexisten en un mismo grupo curso.

- En el aspecto positivo, la Escuela es descrita como entretenida o "bacán", con bonitos dibujos y "libre", es decir permite la libre expresión.

- La Escuela es concebida, reiteradamente, como aburrida o "fome". Los fundamentos difieren dependiendo de la edad de los escolares. Los más pequeños de tercero y cuarto básico -entre mínimo 8 a 10 años- dicen que la Escuela compite con otras actividades como estar en la casa jugando "play" (juego electrónico) o jugando en el parque. Entre los escolares de quinto al octavo básico, la escuela calificad de "fome" porque no entienden los contenidos que los maestros explican en clases o porque "no se profundizan los contenidos, y que todo se queda en juegos o actividades" y además, critican el "desorden" o alboroto.

"Es fome porque no hay reglas, (no sería fome si) fuera más ordenada..." (séptimo básico). "más encima aquí, hacen lo que quieren”. (séptimo básico).

b) Razones para asistir a clases

Se identifican razones de tres tipos: académicas, prosocial e instrumental.

1. Académicas. La utilidad del conocimiento aprendido es una razón poderosa para asistir a clases; el taller de computación es valorado justamente por el acceso al cyber espacio. Se encuentran razones fundadas en la valoración de la educación por parte de los padres y trasmitidas a los escolares; como es obtener nuevos conocimientos y las expectativas de movilidad social asociadas con la educación.

"Porque mi mamá me manda para poder ser alguien en la vida" (Octavo básico).

"Para aprender, porque yo soy responsable (Quinto básico)

2. Prosociales. La valoración de relaciones sociales con compañeros y profesores es una razón reiterada para asistir a clases; otra razón es el encuentro con familiares (el caso de hermanos que viven en casas separadas) y/o alguna pareja sentimental en el colegio.

Se encuentra otra razón para ir a clases y es para mantener relaciones sociales basadas en la violencia.

"Una razón para ir a la escuela es para pelear y comer" (3ro básico) 


\section{Universidade do Extremo Sul Catarinense \\ Revista lbero-Americana de Humanidades, Ciências e \\ Educação \\ unesc

"(vengo a classe) para pegarle al (nombre y apellido de niño) CTM (improperio para niño nombrado)”, (quinto básico).

"Tía (dirigiéndose a la entrevistadora) él solamente viene a la Escuela para hacer desorden, porque tiró todo, un día tiro un cereal en el pasillo principal y no le dijeron nada..." (Cuarto básico).

3. Instrumentales. Entre estas se encuentran: divertirse, evitar alguna sanción u obtener alguna recompensa.

- Divertirse. Este argumento que tiene dos caras. La positiva derivada de las innovaciones pedagógicas de esta Escuela. Los escolares valoran los talleres de: guitarra, computación, danza árabe, calistenia, taekwondo, ping pong, muralismo y cuerpos pintados, entre otros, lideradas por "talleristas" en el marco de la innovación pedagógica en gestación. También valoran juegos colectivos como a la pelota e individuales; hablar por teléfono y jugar con el celular.

- Evitar una sanción. Las instituciones involucradas son la familia y la justicia. En el primer caso es la madre que persuade, obliga y castiga a los que no van al colegio. Los castigos son verbales y físicos; tirar agua para sacar a alguien de la cama o golpes; otra sanción a evitar es "no hacer la cama" (séptimo básico). En el segundo caso, ir a clases es un requisito impuesto para niños y jóvenes con problemas de infracciones legales por el Servicio Nacional de Menores SENAME. (vengo a la Escuela) para no ir al SENAME.. es verdad!!! (Sexto Básico)

- Obtener alguna recompensa, unas académicas y otras, materiales. Los beneficios académicos son obtener calificaciones para aprobar y pasar de curso o participar en un talleactividad académica artística o deportiva- seleccionada. La participación en talleres no es automática y como hay algunos talleres más populares, la escuela emplea las calificaciones como criterio de inclusión en éstos. "(estudio para) participar en el taller que quiero". Entre las recompensas simbólicas y materiales para asistir a clases se encuentra "pelar" o el abuso de poder entre iguales, "comer" y "robar wifi". Aquí es necesario destacar que el acceso un servicio de la escuela es concebido como un acto ilícito.

“(vengo a clases) porque robo wifi y juego y por las notas" (2 séptimo básico). 


\section{Universidade do Extremo Sul Catarinense \\ Revista Ilbero-Americana de Humanidades, Ciências e \\ Educação

unesc

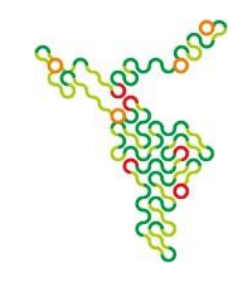

\section{Discusión}

\section{$\underline{\text { La naturalización del robo. }}$}

La experiencia de acceso a la educación, servicios básicos y bienes en general, en una sociedad de consumo está mediado por el intercambio económico monetario. En una sociedad como la chilena, con una alta concentración de bienes y recursos, se generan prácticas como el robo que algunos las conceptualizan como actos delictuales, otros como símbolos ya sea de malestar cultural, ingenio o pillería (LARRAÍN, 2001) y aquellos actos redistributivos como rechazo al orden social imperante. El concepto "robar wifi" en un escolar de tercer grado, implica que el concepto "robar" fue aprendido de sus experiencias cotidianas, de la socialización, en el hogar, el barrio y posiblemente en la propia Escuela.

El "robo" de wifi no tiene repercusión alguna en la escuela, no obstante, esta concepción, que no contempla el coste o repercusión para outro, es además un fenómeno que a nivel social, contribuye con el debilitamiento de la confianza y, por tanto, del mismo tejido social.

\section{El reconocimiento de la diversidad y sus limitaciones.}

Los escolares valoran la libertad que se vive en la Escuela, la posibilidad de integrarse a algún taller, de hacerse de amigos, jugar y también estudiar. Las edades de los escolares en cada curso son muy diversas. Por ejemplo, al cuarto nivel asisten los niños que por edad les corresponde -9 años- los que han quedado rezagados por repetir curso, los desertores que se reincorporan por voluntad propia o para evitar una sanción jurídica. Así, el rango límite puede ser hasta de 18 años, edad de escolaridad obligatoria en Chile.

En el aula existe diversidad de estudiantes, intereses, habilidades, experiencias y madurez física y emocional. La libertad en las aulas permite que cada cual haga lo que desee; salga a integrase en algún taller y se integre o excluya de las actividades académicas propuestas. El aula y la escuela son espacios donde circulan historias, relatos, chistes, palabras, problemáticas o anécdotas que exponen los escolares. En este escenario, los niños y niñas más pequeñas están expuestos a situaciones y experiencias que no son propias de su edad. Por ejemplo, el uso de un lenguaje soez e hipersexuado que los más pequeños lo emplean, imitando a los mayores y que por su desarrollo físico biológico es dudoso que lo vivencien. La diversidad ha entrado al aula y ésta es reflejo de lo que ocurre en la sociedad. La escuela ofrece talleres que cumplen con la función de integrar al estudiante en actividades que impliquen algún aprendizaje, no obstante, como 


\section{Universidade do Extremo Sul Catarinense \\ Revista Ibero-Americana de Humanidades, Ciências e \\ Educação \\ unesc

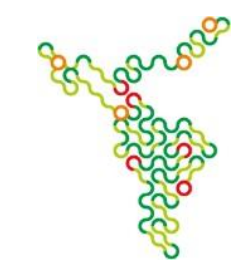

observadores ofrecemos dos interrogantes: ¿cómo aportar al desarrollo de escolares de edades y requerimientos tan dispares en un mismo grupo curso? ¿Cómo educar una sexualización concebida como parte de las relaciones interpersonales y más allá del cuerpo como objeto?

\section{$\underline{\text { La naturalización del abuso de poder entre iguales. }}$}

En el caso estudiado el abuso de poder entre iguales es una práctica habitual, está "naturalizada"; "ir a pelear" es una razón para ir a clases, que involucra a víctimas, victimarios y observadores. Desde el momento que los observadores son pasivos están amparando la agresividad y la violencia, tal como ha sido reportado en otros estudios por ESPINOZA, CASTILLO, GONZÁLEZ, LOYOLA CAMPOS y SANTA CRUZ, 2014); por tanto, la Escuela no está contribuyendo al cuidado de la infancia y está reforzando una práctica cultural de violencia en la convivenia y en las relaciones interpersonales.

La organización de la sociedad chilena, con sus múltiples desigualdades sociales y su historia es una sociedad que engendra prácticas violentas. El problema radica en cómo formar para la democracia y en la diversidad.

\section{Ausencia o puesta en duda de normas sociales}

Desde las dimensiones de la justicia social, la redistribución se expresa en un conjunto de beneficios sociales para escolares y sus famílias. Sin embargo, la redistribución, en el marco de una sociedad de consumo y con repercusiones de la desigualdad en el malestar social, (PNUD, 2017) siempre será insuficiente; el reconocimiento de la diversidad está presente en la escuela, no obstante, la práctica del "dejar hacer", como espectadores en el espacio real o virtual no muestra formas de convivir en la diversidad. La dimensión de representación o su expresión en la participación se ve limitada, por el debilitamiento del tejido social en la sociedad contemporánea de las comunicaciones y por el abuso de poder entre iguales y la falta de reconocimiento de la legitimidad del otro distinto.

El concepto participación implica ser parte, en el caso estudiado, de los escolares como parte de una escuela, de un taller, de una aula, de alguna comunidad virtual, de un grupo de amigos. Este ser parte, sólo opera en tanto hay consenso, objetivos y metas compartidas. En el seno de una subcultura, el problema radica afrontar la discrepancia o la diversidad. La heterogeneidad o diferencia se acalla mediante la acción violenta, golpes o insultos. La experiencia de los escolares en este proyecto educativo fortalece la expresión y la acción individual necesaria, pero insuficiente para la construcción de sentidos colectivos. 


\section{Universidade do Extremo Sul Catarinense \\ Revista Ibero-Americana de Humanidades, Ciências e \\ Educação \\ UneSC Produção e democratização do conhecimento na lbero-América}

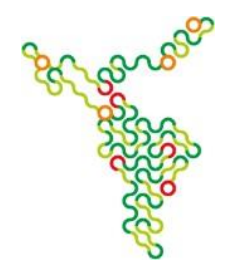

La ausencia de límites por parte de los formadores y la práctica del “dejar hacer”, enseña, socializa a la gestión de sí mismo desde el espacio privado y desde el ámbito individual, debilitando el ejercicio de consensuar acuerdos, de aprender a convivir en la diversidad, de construir alianzas en pos del bien común más allá de la subcultura o el grupo de pares.

\section{A modo de conclusión}

Las razones de por qué ir a la escuela, muestra la experiencia de los escolares y los alcances y limitaciones de la socialización secundaria. Aquellos que confían en la educación como herramienta de movilidad social, siguen el camino de muchos otros que así lo han hecho. Los que asisten a la escuela por algunas de las tantas razones instrumentales, nos permite develar aspectos de un malestar cultural; una socialización que permite la naturalización de la violencia y el abuso de poder entre iguales.

Lo aquí presentado es una muestra de las injusticias en la sociedad y en la escuela. Para fomentar la justicia social, es necesario tener presentes las tres dimensiones -redistribución, reconocimiento y representación- y desde un accionar sociocultural es necesario generar espacios que fortalezcan lazos de confianza, las prácticas para fortalecer el tejido social y convivir en la diversidad. La gran deuda nuestra sociedad chilena es consensuar la forma de organización social para la que estamos formando, que nos permita vivir en paz y promover una cultura para la justicia social.

\section{Referencias}

BERGER, P.; LUCKMANN, T. The social construction of reality. LONDON: Penguin University Book. 1976.

CONDE, F. Análisis sociológico del sistema de discursos. Colección Cuadernos Metodológicos, 43. MADRID: CIS - Centro de Investigaciones Sociológicas. 2009.

CUENCA, R. Sobre justicia social y su relación con la educación en tiempos de desigualdad. Revista Internacional de Educación para la Justicia Social (RIEJS), MADRID, v. 1, n.1, p. 7993, 2012.

ESPINOZA DÍAZ, O.; CASTILLO GUAJARDO, D.; GONZÁLEZ, L. E.; LOYOLA CAMPOS, J.; SANTA CRUZ GRAU, E. Deserción escolar en Chile: un estudio de caso en relación con factores intraescolares. Educación Educadores. v. 17, n. 1, p. 32-50. 2014.

FRASER, N. Escalas de justicia. Barcelona: Herder, 2008.

GOICOVIC, I. Educación, deserción escolar e integracion laboral juvenil. Última década, v 10, n. 
16, p. 11-52. Marzo, 2002.

LARRAÍN, J. (2001). Identidad Chilena. Santiago CHILE: Ediciones LOM. 2001.

PROGRAMA DE LAS NACIONES UNIDAD PARA EL DESARROLLO (PNUD). Desiguales. Orígenes, cambios y desafíos de la brecha social en Chile. Santiago de CHILE: Uqbar Editores, 2017. Disponible en: https://www.desiguales.org/s/DESIGUALES_reimp_Present-f4bt.pdf

MURILLO, J.; BALAVI, G. Educación, Democracia y Justicia Social. Revista Internacional de Educación para la Justicia Social (RIEJS), v .5, n. 1, p. 13-34. 2016.

MURILLO, F. J.; HERNÁNDEZ-CASTILLA, R. Hacia un concepto de Justicia Social. REICE. Revista Iberoamericana sobre Calidad, Eficacia y Cambio en Educación. (REICE). v. 9, n. 4, p. 7-23. 2011.

RAWLS, J. Teoría de la justicia. Ciudad de MEXICO: Fondo de Cultura Económica. 2008.

\section{Agradecimentos}

A Natalia Campos Osorio y Joaquín Astudillo Miranda, ambos estudiantes de cuarto año de Sociología por la realización de la entrevistas. 